\title{
Smart and Sustainable Manufacturing Systems
}

László Monostori ${ }^{1,2}$ and József Váncza ${ }^{2,3}$

DOl: 10.1520/SSMS20200063

Lessons Learned from the COVID19 Pandemic and Their Possible Consequences on Manufacturing 


\section{TECHNICAL NOTE}

Manuscript received September 14, 2020; accepted for publication September 22, 2020; published online $x x x x x x, x x x x$.

1 Institute for Computer Science and Control, H-1111 Kende u. 13-17, Budapest, Hungary

(Corresponding author), e-mail: monostori.laszlo@sztaki.hu, (iD https://orcid.org/0000-00018692-8640

2 Department of Manufacturing Science and Technology, Budapest University of Technology and Economics, $\mathrm{H}-1111$, Müegyetem rkp. 3, Budapest, Hungary

3 Institute for Computer Science and Control, H-1111, Kende u. 13-17, Budapest, Hungary, (1) https:// orcid.org/0000-0003-00540560

\section{László Monostori ${ }^{1,2}$ and József Váncza ${ }^{2,3}$ \\ Lessons Learned from the COVID-19 Pandemic and Their Possible Consequences on Manufacturing}

\section{Reference}

L. Monostori and J. Váncza, "Lessons Learned from the COVID-19 Pandemic and Their Possible Consequences on Manufacturing," Smart and Sustainable Manufacturing Systems

https://doi.org/10.1520/SSMS20200063

\section{ABSTRACT}

Manufacturing became one of the main targets of the coronavirus disease 2019 pandemic. Important questions such as how to deal with the drastic changes (up and down) in demand, and how to keep production ongoing with a decimated workforce and crippled supply chains arose. This technical note gives a short assessment of the praiseworthy reactions of the manufacturing industry, which prevented society from sinking into an even deeper crisis. The pandemic, at the same time, pointed out some weaknesses of present-day manufacturing. Possible long-term consequences of the lessons given and perhaps learned are summarized herein, with a focus on substantial changes and new paradigms that could provide an appropriate armory for the manufacturing industry when responding to similar or even more drastic situations in the future. However, it is yet undecided as to whether the ongoing changes in manufacturing will be accelerated or dismissed, causing manufacturers to fall back into the old groove. Some related questions and dilemmas are also exposed in the end of the paper.

\section{Keywords}

manufacturing, coronavirus disease 2019, flexibility, reconfigurability, changeability, robustness, resilience, sustainability

\section{Introduction}

On March 11, 2020, the World Health Organization declared the coronavirus disease 2019 (COVID-19) caused by the new coronavirus (severe acute respiratory coronavirus 2) pandemic. The spread of COVID-19 is accelerating: the first million infections were registered within 100 days, whereas in the late summer, only 100 hours were needed for a similar jump. At the time of writing, we are in the phase of worldwide spread, and most regions are 
suffering from a second wave. Countries reacted to the extraordinary challenges in their own ways, in quite a discord. The various industry sectors were also affected differently, some even positively. The turning point will be the worldwide availability of a vaccine or some reliable treatment, and after a while will come the post-COVID-19 era, when recovery can start following the end of the pandemic. However, we should not wait to learn the lessons or draw conclusions for so long. Preparations for this period must start right now, even though the future is burdened with a number of uncertain factors (of which COVID-19 is only one). This short paper-a kind of tentative forecast-is aimed at this goal, with a focus mostly on manufacturing.

\section{Assessment of the Situation of Manufacturing under the Pandemic}

At the beginning of the pandemic, production volume in most of the industry sectors plummeted. The generic lockdown measures drastically restricted both the capacity of workforce and demand generated by them. Supply chains were crippled by underperforming production nodes and transportation links. Loss of jobs on a large scale immediately followed, dragging industrial production into a vicious cycle. At the same time, extraordinary demand arose for some medicaments and special medical equipment, e.g. respirators, and for appliances, like face shields and masks as well as medical gowns. Most of the producers were not able to fulfill the extra demand because of capacity problems and supply difficulties. Others, typically in the process industries, were able to make appropriate changes and introduced new product variants or extended their product families. Larger effort was needed in the discrete part manufacturing, e.g., by switching from car making to the production of respirators. In many cases, design of new products or modifications of existing ones became necessary. Threedimensional printing and additive manufacturing received new stimuli. As air transports almost totally stopped for a while, the various modes of land transport gained increased importance; however, the fallout of the human workforce also hit this segment. There was a relief, albeit temporal, on the pressure on the environment. Nevertheless, this did not lead to a substantial change in the mindset of manufacturers. The grave conflict between the objectives of competitive manufacturing and those of sustainable manufacturing has prevailed thus far.

\section{Possible Long-term Consequences}

In what follows, we try to enumerate and analyze some long-term consequences of the COVID-19 pandemic on manufacturing.

\section{PRODUCTS, PRODUCT VARIANTS, AND MIX}

Companies responding to fluctuating demand of a broad variety of products and accompanied services will have a better chance of survival because they need special faculties of changeability, adaptiveness, and responsiveness to remain competitive. In the so-called high-mix and low-volume (HMLV) production environments, the structure as well as the planned and actual behavior of the systems should be tailored time and again to the changing conditions. Floating above all the waves generated by external sources (market demand, suppliers) or internal causes (resource availability, inventory levels), HMLV companies can show a consistently stable, high-level performance especially in terms of quality and service level. Modularization of products and the development of part families is, however, a substantial enabling condition for successful HMLV production.

\section{TECHNOLOGIES, MACHINE TOOLS, AND MANUFACTURING SYSTEMS}

Additive manufacturing will receive even more emphasis, in combination with traditional, subtractive technologies, with broader material assortment, including composites, and smart materials integrated with sensors and actuators. Bioinspired materials will find newer and newer applications to satisfy the industrial and environmental requirements. ${ }^{1}$ Increased flexibility, robustness, and reconfigurability ${ }^{2}$ of machine tools and manufacturing systems will be a fundamental characteristic of the manufacturing automation. The system elements will possess a 
higher-level of autonomy compared with their present states, and platforms of production will evolve together with product families. ${ }^{3}$ Every form of cooperation, such as human-human, human-machine, and machinemachine, will be integral elements of production systems. ${ }^{4}$ Systems that can function with different levels of human-robot involvement should be developed. Agent-based, holonic control architectures are better suited for dealing with the unexpected. ${ }^{5,6}$ The application of the digital twins, together with predictive engineering, ${ }^{7}$ can lead to anticipatory rather than reactive systems. ${ }^{8}$ Even new manufacturing system structures with higher levels of changeability ${ }^{9}$, e.g., island structures, will gain ground. Urban factories ${ }^{10}$ could cope with a significant portion of challenges faced during the COVID-19 pandemic.

\section{SUPPLY CHAINS AND PRODUCTION NETWORKS}

The robustness and resilience of supply chains and production networks, ${ }^{11}$ i.e., their ability to cope with external and internal disruptions and disturbances, will gain further importance. The investigation and exploration of the relations of supply chains' robustness, complexity, ${ }^{12}$ and efficiency, not forgetting the environmental aspects either, will be a key research field in order to find appropriate trade-offs between them. ${ }^{13}$ The solely profit-centric thinking in this field is to be given up. ${ }^{13}$ New inventory-handling policies will be introduced, and even existing supply chain structures will be redesigned. Expectedly, the length of supply chains will be shortened, and their width increased; multiple sourcing will be more frequent. The vertical integration within companies, i.e., increase the depth of their own value creation, will be strengthened. ${ }^{14}$ Supply chains' restructuring can go hand in hand with the reduction of the transportation-related carbon dioxide emission for the benefit of the environment. ${ }^{13}$ New supply chain paradigms, such as the low-certainty need ${ }^{15}$ or the viable ones ${ }^{16}$ will quickly find their place. All of these will be supported by further digitalization and the use of cyber-physical solutions. ${ }^{17}$ Lessons learned from the pandemic era can even accelerate the development and wide use of autonomous cars, particularly of trucks.

\section{PLANNING AND OPERATIONS MANAGEMENT}

In any production network, the efficiency of operations and the economical use of material, energy, and production resources hinge on the local decisions of the partners who can rely on asymmetric and partially incomplete and inconsistent information. So as to achieve and maintain a systemwide network function, information sharing and coordination are not sufficient: the partners must have cooperative attitudes both to resolve their conflicting interests and to handle common resources of the global environment in a sustainable manner. ${ }^{18}$ Planning concerns decisions about future courses of action that are mostly based on expectations (e.g., demand forecast, resource availability, and material supply). Advanced methods of machine learning can greatly improve the reliability of these predictions. Efficient local planning that results in executable, cost-efficient, and robust production plans and schedules is the key to predictable behavior.

The proliferation of massive sensing, data processing, and storage techniques characteristic to cyber-physical production systems ${ }^{17}$ open new avenues for (big) data analytics ${ }^{19}$ in handling the growing complexity of production management. However, conformance with engineering background knowledge captured in existing models and systems is a must. Simulation still provides a very efficient set of tools for analyzing the complex impact of decisions that are related both to the structure and behavior of a production system. ${ }^{20}$ Fine granularity of details, semantic clarity, transparency, conformance to real systems, and a rich assortment of available modeling and evaluation tools are all on the side of merits, whereas the main shortcomings are limited generality, potentially haphazard future scenarios, and extreme computational load. Here, by making use of digital twins to capture all levels of production, one can expect the combination of the strengths of model- and data-driven analytics.

\section{HUMAN-CENTERED PRODUCTION}

The inclusion of human workers in automated production processes is nowadays receiving growing support by underlying technological and scientific development. Industrial production faces a growing need to reclaim the versatility and intuitive problem solving of human workforce previously lost to industrial automation. Fundamental employee requirements include flexibility and multiple (including digital) skills. The pandemic 
strengthened the demand for and the possibility of remote work supported by augmented and virtual realities. ${ }^{21,22}$ Artificial intelligence and machine learning technologies will aid activity at all the levels of a company's hierarchy. The pandemic era threw light on the importance of the health state of the workforce. As a consequence, a kind of "predictive maintenance" of the operational staff will be employed.

\section{Questions and Dilemmas}

We are convinced that the above potential responses to the problems exposed or caused by the pandemic could strengthen manufacturing industry along all the main dimensions of sustainable production, i.e., economic, environmental, and social dimensions. However, a number of crucial questions and dilemmas prevail whose resolution substantially confine the paths to prospective changes:

- Can the COVID-19 pandemic be considered the start of general deglobalization?

- Is there any chance that lower environmental load experienced during the pandemic will not be an extraordinary, nonrecurring experience?

- Is competitive and, at the same time, sustainable manufacturing a realistic option at substantially lower economies of scale?

- Can we find a balance between optimization, robustness, and resilience in manufacturing systems and supply chains?

- Will the basic efficiency-centric (i.e., profit) mindset turn to a more cooperative one in the post-COVID-19 era?

- Will governmental and transnational regulations provide incentives for a more cooperative manufacturing setting?

- Will the role of humans in manufacturing change as a consequence of the COVID-19 pandemic?

\section{Conclusions}

The COVID-19 pandemic confronted manufacturing industry with an unprecedented situation. Generally, its reactions were appropriate, sometimes even praiseworthy. At the same time, the extraordinary challenges pointed out some weaknesses and vulnerabilities of the present solutions and structures. It remains undecided whether the lessons will be learned and the change of manufacturing paradigms will be accelerated accordingly or whether the development trends will be continued along their former trajectories. Manufacturing for sure is ready to change for the better.

\section{ACKNOWLEDGMENTS}

This research has been supported by the European H2020 EPIC grant no. 739592 and the GINOP-2.3.2-15-201600002 grant of Hungary.

\section{References}

1. G. Byrne, D. Dimitrov, L. Monostori, R. Teti, F. van Houten, and R. Wertheim, "Biologicalisation: Biological Transformation in Manufacturing," CIRP Journal of Manufacturing Science and Technology 21 (2018): 1-32, https:// doi.org/10.1016/j.cirpj.2018.03.003

2. Y. Koren, U. Heisel, F. Jovane, T. Moriwaki, G. Pritschow, G. Ulsoy, and H. Van Brussel, "Reconfigurable Manufacturing Systems," CIRP Annals 48, no. 2 (1999): 527-540, https://doi.org/10.1016/S0007-8506(07)63232-6

3. T. Tolio, D. Ceglarek, H. A. ElMaraghy, A. Fischer, S. J. Hu, L. Laperrière, S. T. Newman, and J. Váncza, "SPECIES-Coevolution of Products, Processes and Production Systems," CIRP Annals 59, no. 2 (2010): 672-693, https://doi.org/10. 1016/j.cirp.2010.05.008

4. L. Wang, R. Gao, J. Váncza, J. Krüger, X. V. Wang, S. Makris, and G. Chryssolouris, "Symbiotic Human-Robot Collaborative Assembly," CIRP Annals 68, no. 2 (2019): 701-726, https://doi.org/10.1016/j.cirp.2019.05.002

5. L. Monostori, J. Váncza, and S. R. T. Kumara, “Agent-Based Systems for Manufacturing,” CIRP Annals 55, no. 2 (2006): 697-720, https://doi.org/10.1016/j.cirp.2006.10.004 
6. P. Valckenaers and H. Van Brussel, Design for the Unexpected: From Holonic Manufacturing Systems Towards a Humane Mechatronics Society (Amsterdam, the Netherlands: Elsevier, 2015), https://doi.org/10.1016/C2014-0-04226-8

7. A. Kusiak, "Smart Manufacturing," International Journal of Production Research 56, nos. 1-2 (2018): 508-517, https://doi. org/10.1080/00207543.2017.1351644

8. R. X. Gao, L. Wang, M. Helu, and R. Teti, “Big Data Analytics for Smart Factories of the Future,” CIRP Annals 69, no. 2 (2020): 668-692, https://doi.org/10.1016/j.cirp.2020.05.002

9. H.-P. Wiendahl, H. A. ElMaraghy, P. Nyhuis, M. F. Zäh, H.-H. Wiendahl, N. Duffie, and M. Brieke, "Changeable Manufacturing - Classification, Design and Operation,” CIRP Annals 56, no. 2 (2007): 783-809, https://doi.org/10. 1016/j.cirp.2007.10.003

10. C. Herrmann, M. Juraschek, P. Burggräf, and S. Kara, "Urban Production: State of the Art and Future Trends for Urban Factories,” CIRP Annals 69, no. 2 (2020): 764-787, https://doi.org/10.1016/j.cirp.2020.05.003

11. G. Lanza, K. Ferdows, S. Kara, D. Mourtzis, G. Schuh, J. Váncza, L. Wang, and H.-P. Wiendahl, "Global Production Networks: Design and Operation," CIRP Annals 68, no. 2 (2019): 823-841, https://doi.org/10.1016/j.cirp.2019.05.008

12. W. ElMaraghy, H. ElMaraghy, T. Tomiyama, and L. Monostori, "Complexity in Engineering Design and Manufacturing," CIRP Annals 61, no. 2 (2012): 793-814, https://doi.org/10.1016/j.cirp.2012.05.001

13. J. Monostori, "Beyond the Profit Motive: Environmentally Conscious (Re)design of Supply Chain Structures," Procedia CIRP 93 (2020): 808-813, https://doi.org/10.1016/j.procir.2020.03.033

14. F. T. Piller, Ten Propositions on the Future of Digital Business Models for Industry 4.0 in the Post-Corona Economy (Berlin: Plattform Industrie 4.0, 2020), http://dx.doi.org/10.2139/ssrn.3617816.

15. D. Ivanov and A. Dolgui, "Low-Certainty-Need (LCN) Supply Chains: A New Perspective in Managing Disruption Risks and Resilience," International Journal of Production Research 57, nos. 15-16 (2019): 5119-5136, https://doi.org/10.1080/ 00207543.2018.1521025

16. D. Ivanov and A. Dolgui, "Viability of Intertwined Supply Networks: Extending the Supply Chain Resilience Angles Towards Survivability. A Position Paper Motivated by COVID-19 Outbreak," International Journal of Production Research 58, no. 10 (2020): 2904-2915, https://doi.org/10.1080/00207543.2020.1750727

17. L. Monostori, B. Kádár, T. Bauernhansl, S. Kondoh, S. Kumara, G. Reinhart, O. Sauer, G. Schuh, W. Sihn, and K. Ueda, "Cyber-Physical Systems in Manufacturing," CIRP Annals 65, no. 2 (2016): 621-641, https://doi.org/10.1016/j.cirp.2016. 06.005

18. J. Váncza, L. Monostori, D. Lutters, S. R. Kumara, M. Tseng, P. Valckenaers, and H. Van Brussel, "Cooperative and Responsive Manufacturing Enterprises,” CIRP Annals 60, no. 2 (2011): 797-820, https://doi.org/10.1016/j.cirp.2011. 05.009

19. F. Tao, Q. Qi, A. Liu, and A. Kusiak, “Data-Driven Smart Manufacturing," Journal of Manufacturing Systems 48, Part C (July 2018): 157-169, https://doi.org/10.1016/j.jmsy.2018.01.006

20. B. Kádár, A. Lengyel, L. Monostori, Y. Suginishi, A. Pfeiffer, and Y. Nonaka, "Enhanced Control of Complex Production Structures by Tight Coupling of the Digital and the Physical Worlds," CIRP Annals 59, no. 1 (2010): 437-440, https://doi. org/10.1016/j.cirp.2010.03.123

21. A. Y. C. Nee, S. K. Ong, G. Chryssolouris, and D. Mourtzis, "Augmented Reality Applications in Design and Manufacturing,” CIRP Annals 61, no. 2 (2012): 657-679, https://doi.org/10.1016/j.cirp.2012.05.010

22. X. Wang, S. K. Ong, and A. Y. C. Nee, "Real-Virtual Components Interaction for Assembly Simulation and Planning," Robotics and Computer-Integrated Manufacturing 41 (October 2016): 102-114, https://doi.org/10.1016/j.rcim.2016.03. 005 